\title{
Blockade of OX40/OX40L pathway combined with ethylene- carbodiimide-fixed donor splenocytes induces donor-specific allograft tolerance in presensitized recipients
}

\author{
Xingqiang Lai ${ }^{1 \#}$, Zhongpeng Yao ${ }^{1 \#}$, Fen Ning $^{2}$, Lei Zhang ${ }^{1}$, Jiali Fang ${ }^{1}$, Guanghui Li ${ }^{1}$, Lu Xu ${ }^{1}$, \\ Yunyi Xiong ${ }^{1}$, Luhao Liu ${ }^{1}$, Rongxin Chen ${ }^{1}, J^{1}$ jiie Ma ${ }^{1}$, Zheng Chen ${ }^{1}$ \\ ${ }^{1}$ Organ Transplant Center, The Second Affiliated Hospital of Guangzhou Medical University, Guangzhou 510260, China; ${ }^{2}$ Guangzhou Institute of \\ Pediatrics, Women and Children's Medical Center, Guangzhou Medical University, Guangzhou 510623, China \\ Contributions: (I) Conception and design: X Lai; (II) Administrative support: Z Chen; (III) Provision of study materials or patients: F Ning, L Zhang, \\ J Fang, G Li; (IV) Collection and assembly of data: X Lai, Z Yao, Y Xiong, L Liu; (V) Data analysis and interpretation: L Xu, R Chen, J Ma; (VI) \\ Manuscript writing: All authors; (VII) Final approval of manuscript: All authors. \\ \#These authors contributed equally to this work. \\ Correspondence to: Zheng Chen. Organ Transplant Center, The Second Affiliated Hospital of Guangzhou Medical University, No. 250 Changgang \\ East Road, Haizhu District, Guangzhou 510260, China. Email: docchenzheng@163.com.
}

Background: Memory $\mathrm{T}$ cells (Tms) are the major barrier preventing long-term allograft survival in presensitized transplant recipients. The OX40/OX40L pathway is important in the induction and maintenance of Tms.

Methods: In this study, we added anti-OX40L mAb to ethylene-carbodiimide-fixed donor splenocytes (ECDI-SPs) - a method which is effective in inducing allograft tolerance in non-presensitized mouse heart transplant model. Recipient mice received heart transplantation after 6 weeks of donor skin presensitization and were treated with anti-OX40L mAb, ECDI-SPs or anti-OX40L mAb + ECDI-SPs, respectively.

Results: Our data showed that the combination of ECDI-SPs and anti-OX40L mAb induced donorspecific tolerance in skin-presensitized heart transplant recipients, with the mechanism for this being associated with suppression of Tms and upregulation of $\mathrm{CD} 4^{+} \mathrm{CD} 25^{+} \mathrm{Foxp} 3^{+} \mathrm{T}$ regulatory cells (Tregs). Importantly, CD $25^{+}$T-cell depletion in the combined therapy-treated recipients broke the establishment of allograft tolerance, whereas adoptive transfer of presensitization-derived $\mathrm{T}$ cells into tolerant recipients suppressed Tregs expansion and abolished established tolerance.

Conclusions: Blockade of OX40/OX40L pathway in combination with ECDI-SPs appears to modulate the Tms/Tregs imbalance so as to create a protective milieu and induce graft tolerance in presensitized recipients.

Keywords: Memory T cells (Tms); OX40/OX40L pathway; ethylene-carbodiimide-fixed donor splenocytes (ECDI-SPs); regulatory $\mathrm{T}$ cells; tolerance

Submitted Nov 25, 2019. Accepted for publication Dec 11, 2019.

doi: 10.21037/atm.2019.12.146

View this article at: http://dx.doi.org/10.21037/atm.2019.12.146

\section{Introduction}

Transplant recipients can develop alloreactive memory $\mathrm{T}$ cells (Tms) after exposure to alloantigen from previous transplantations, pregnancies, blood transfusions, and by continuous exposure to bacteria or viruses (1). Tms mediate acute and chronic graft rejection and impede induction of transplant tolerance in both primary and secondary transplants (2). Previous studies have demonstrated that blocking CD28 and CD40/CD154 costimulatory pathway is effective in promoting allograft survival in naïve recipients, 
but these strategies were ineffective in those primed with donor-specific antigen $(3,4)$.

The OX40/OX40L costimulatory pathway is a member of the tumor necrosis receptor superfamily (TNFR) (5-7). OX40 is expressed on activated T cells $(8,9)$, while OX40L is expressed in dendritic cells (DCs), B cells, vascular endothelial cells, and activated T cells (10-12). Interactions of OX40 and OX40L between T cells and APCs mediate T-cell activation $(10,11)$, clonal expansion, and cytokine production $(5,13)$, whereas OX40-OX40L interactions between $\mathrm{T}$ cells are involved in late $\mathrm{T}$-cell proliferation and prolonging $\mathrm{T}$ cell survival $(14,15)$. In addition, OX40/ OX40L pathway plays a critical role in the generation of Tms when other costimulatory pathways are blocked (16-18). OX40 has been found to be expressed in $\mathrm{T}$ regulatory cells (Tregs), while OX40/OX40L pathway has been identified to hinder Tregs induction and function $(7,19,20)$.

Targeting the OX40/OX40L pathway, specifically memory cells, has proven to be a promising approach and could be therapeutically important for organ transplantation. However, although the blockade of OX40/ OX40L pathway markedly prevents Tms, thus far this method has only been able to temporarily extend the survival of grafts in presensitized recipients (21). Given this, using a combination of anti-OX40L mAb and other protocols is suggested for prolonging graft survival in presensitized recipients (21). Recently, studies have revealed that intravenous infusion of ethylene-carbodiimide-fixed donor splenocytes (ECDI-SPs) can therapeutically induce antigen-specific tolerance in vivo $(22,23)$. The infusion of ECDI-SPs has recently been shown to induce donorspecific tolerance in mouse islet cells and heart transplant models $(24,25)$, and prolong mouse vascularized skin allograft survival (26). Base on the findings above, we speculated that blocking the OX40/OX40L pathway would prevent the functions of Tms and help to induce Tregs, so as to strengthen the tolerogenic function of ECDI-SPs. In this study, by using a skin-presensitized heart transplant mouse model, we aimed to verify if OX40/OX40L pathway combined with ECDI-SPs treatment could induce donorspecific transplant tolerance in presensitized recipients.

\section{Methods}

\section{Animals}

Male BALB/c, C57B/6, and C3H mice (6-8 weeks old) purchased from the Experimental Animal Center of Sun Yat-sen University were used as donors, recipients and, third-party donor controls, respectively. All animals were housed and bred in a pathogen-free facility which was provided by the Experimental Animal Center of Guangzhou Medical University. All animal experiments were approved by the Institutional Animal Care and Use Committee of Guangzhou Medical University and conformed to the Institutional Guidelines of Guangdong Province.

\section{Skin presensitization and cardiac transplantation}

Full-thickness BALB/c mice (donor) trunk skin tissues (square pieces, $1 \mathrm{~cm} \times 1 \mathrm{~cm}$ ) were engrafted onto the lumbar region of $\mathrm{C} 57 \mathrm{~B} / 6$ mice (recipients). Six weeks after primary skin-presensitization, $\mathrm{BALB} / \mathrm{c}$ hearts were acquired and transplanted into abdomens of $\mathrm{C} 57 \mathrm{~B} / 6$ recipients as previously described (27). Graft survival was monitored daily by direct abdominal palpation of heart beating. Rejection was defined as the complete loss of palpable heart beating and considered as the ending event. Recipients were followed up to the day when an ending event occurred, or for 100 days if recipients survived for more than 100 days.

\section{Preparation of ECDI-SPs and anti-OX40L mAb administration}

ECDI-fixed donor splenocytes were prepared as previously described (28). Splenocytes harvested from donor $(\mathrm{BALB} / \mathrm{c})$ mice were incubated with ECDI $(150 \mathrm{mg} / \mathrm{mL}$ per $3.2 \times 10^{8}$ cells; Sigma, USA) on ice for 1 hour. After washing and cell counting, a total of $1 \times 10^{8}$ ECDI-SPs in $200 \mu \mathrm{L}$ PBS were injected intravenously through the penile dorsal vein on day $-7,0,7$, and 14 in relation to the day of heart transplantation. Anti-OX40L mAb (BioXcell, USA) was injected intraperitoneally ( $0.5 \mathrm{mg}$ per mouse) on days $0-10$. Isotype-matched rat immunoglobulin $\mathrm{G}$ (IgG) (SigmaAldrich, USA) was used as the control $(0.5 \mathrm{mg}$, days $0-10)$.

\section{Experimental groups}

To test the effect of anti-OX40L mAb combined with ECDI-SPs, skin-presensitized heart allograft recipient mice were randomly assigned $(n=5-6)$ as follows: Group 1, untreated; Group 2, treated with ECDI-SPs; Group 3 , treated with anti-OX40L mAb; Group 4, received combined therapy of ECDI-SPs and anti-OX40L mAb; Group 5, treated with isotype control IgG; Group 6, treated 
with isotype control IgG in combination with ECDI-SPs.

\section{Flow cytometry analysis}

Phenotypic analysis of $\mathrm{CD} 4^{+} \mathrm{CD} 44^{+}$and $\mathrm{CD} 8^{+} \mathrm{CD} 44^{+}$ Tms and identification of $\mathrm{CD} 4^{+} \mathrm{CD} 25^{+} \mathrm{Foxp}^{+}$Tregs were analyzed by flow cytometry (29). Splenocytes isolated from recipients were stained with anti-mouse CD4-FITC, CD8a-PE-Cy7, CD25-PE, CD44-BV421, and Foxp3-Alexa Fluor 647 according to the manufacturer's instructions. Cell samples were acquired using a Beckman flow cytometer (Beckman Coulter, USA) and were analyzed using Flowjo 7.6 software. Appropriate isotype-matched IgG was used as the control. All of the flow cytometry Abs were purchased from BD Biosciences unless otherwise indicated.

Circulating anti-donor IgG and $\operatorname{IgM}$ antibodies were measured by flow cytometry as previously described (30). Briefly, thymocytes harvested from donor thymus were blocked with Fc blocker $\left(1 \mu \mathrm{L}\right.$ per $5 \times 10^{5}$ cells; BD Biosciences) and incubated with recipient plasma (1:4 dilution) on ice for 1 hour. After washing twice, cells were stained with anti-mouse IgG-APC (BD Biosciences) and IgM-PE (BD Biosciences) and analyzed by flow cytometer. Negative control thymocytes were incubated with naïve mouse plasma.

\section{Mixed lymphocyte reactions (MLRs)}

Donor $(\mathrm{BALB} / \mathrm{c}) \mathrm{CD}^{+} \mathrm{T}$ cells $(\mathrm{CD} 3$-positive selection; Miltenyi Biotec, Germany) acquired from spleens were treated with carboxyfluorescein succinimidyl amino ester (CFSE, $0.5 \mathrm{mg} / \mathrm{mL}$; Sigma-Aldrich), seeded $\left(1 \times 10^{5} /\right.$ well) in triplicate and used as responders. Recipient $(\mathrm{C} 57 \mathrm{~B} / 6)$ splenic CD $11 \mathrm{c}^{+}$dendritic cells (DCs, Miltenyi Biotec, Germany) were treated with mitomycin C $(50 \mu \mathrm{g} / \mathrm{mL}$; Sigma-Aldrich), seeded as $2.5 \times 10^{4} /$ well, and used as stimulators. After coincubation for 96 hours, cells were harvested and T-cell proliferation was quantitatively detected by CFSE dilution using flow cytometry.

\section{Cytokine assay}

Recipient serum samples at different post-transplant time points and culture supernatants from MLRs were obtained. Quantitative analysis of inflammatory cytokines (IFN- $\gamma$ and IL-6) levels was conducted using ELISA kits (Neobioscience, Shenzhen, China) according to the manufacturer's instructions.

\section{CD25+ cell depletion}

To investigate whether Tregs play a determinant role in tolerant induction, depletion of $\mathrm{CD} 25^{+}$cells was performed by using anti-CD25 mAb. Presensitized cardiac transplant mice treated with anti-OX40L mAb and ECDI-SPs were injected with $0.5 \mathrm{mg} /$ mouse of rat anti-mouse CD25 mAb (BioXcell, USA) intraperitoneally on days $-2,0$, and 2. Rat IgG1 (0.5 mg/mouse; Sigma-Aldrich) injections into the same group of recipients on similar time points served as isotype-matched controls. After $\mathrm{CD} 25^{+}$cell depletion, $\mathrm{CD} 4^{+} \mathrm{CD} 25^{+} \mathrm{Foxp}^{+}{ }^{+}$Tregs frequencies were analyzed by flow cytometry.

\section{Adoptive transfer of purified T cells}

$\mathrm{CD}^{+} \mathrm{T}$ cells were acquired (CD3-positive selection; Miltenyi Biotec, Germany) from primed C57B/6 mice 6 weeks after presensitization by either $\mathrm{BALB} / \mathrm{c}$ or $\mathrm{C} 3 \mathrm{H}$ skin transplantation. These $\mathrm{CD}^{+} \mathrm{T}$ cells $\left(5 \times 10^{6} ;>97 \%\right.$ purity) were injected intravenously through the penile dorsal vein into tolerogenic recipients treated by ECDI-SPs combined with anti-OX40L mAb on post operation day (POD) 30 or POD $100(\mathrm{n}=5)$.

\section{Statistical analysis}

All statistical data was analyzed using SPSS19.0 software (IBM Company, USA). Allograft survival analysis was performed using Kaplan-Meier analysis, and difference between groups was compared by log-rank test. Flow cytometry and ELISA results were expressed as mean $\pm \mathrm{SD}$ and analyzed using one-way ANOVA. Differences with $\mathrm{P}<0.05$ were considered significant.

\section{Results}

\section{Anti-OX40L mAb inbibited expansion of Tms after skin presensitization and heart transplantation}

In this study, we found that the frequency of $\mathrm{CD} 4^{+} \mathrm{CD} 44^{+}$ and $\mathrm{CD} 8^{+} \mathrm{CD} 44^{+} \mathrm{Tms}$ in spleens significantly increased after skin-presensitization, and maintained at a high level for an extended period. When heart transplantation was performed, the frequency of $\mathrm{CD} 4^{+} \mathrm{CD} 44^{+}$and $\mathrm{CD} 8^{+} \mathrm{CD} 44^{+}$ Tms increased to a much higher level (Figure 1A,B). Importantly, anti-OX40L mAb treatment, when compared with the corresponding untreated skin-presensitized control mice, significantly decreased in frequencies of splenic 
A

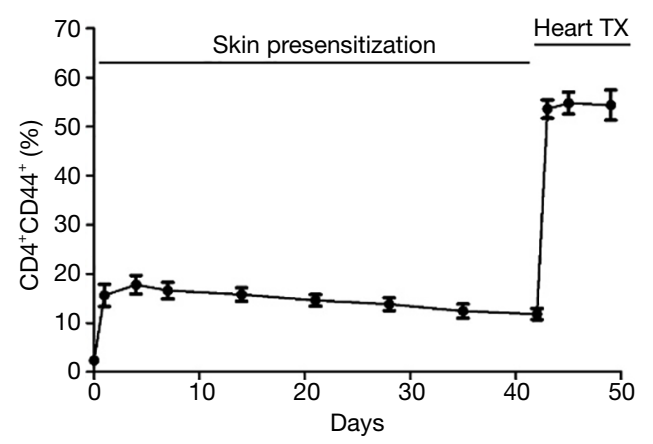

C

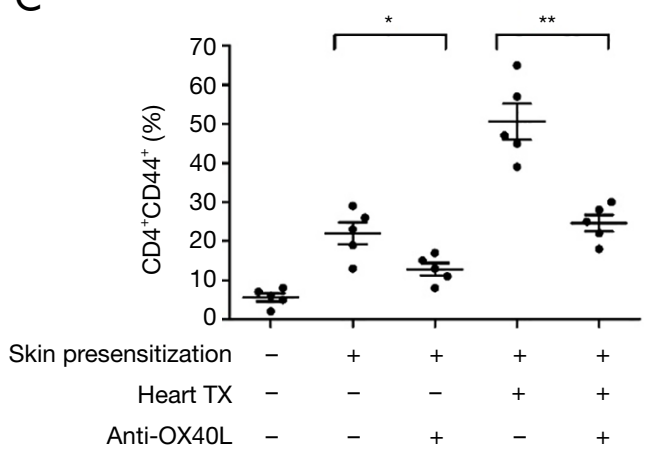

B
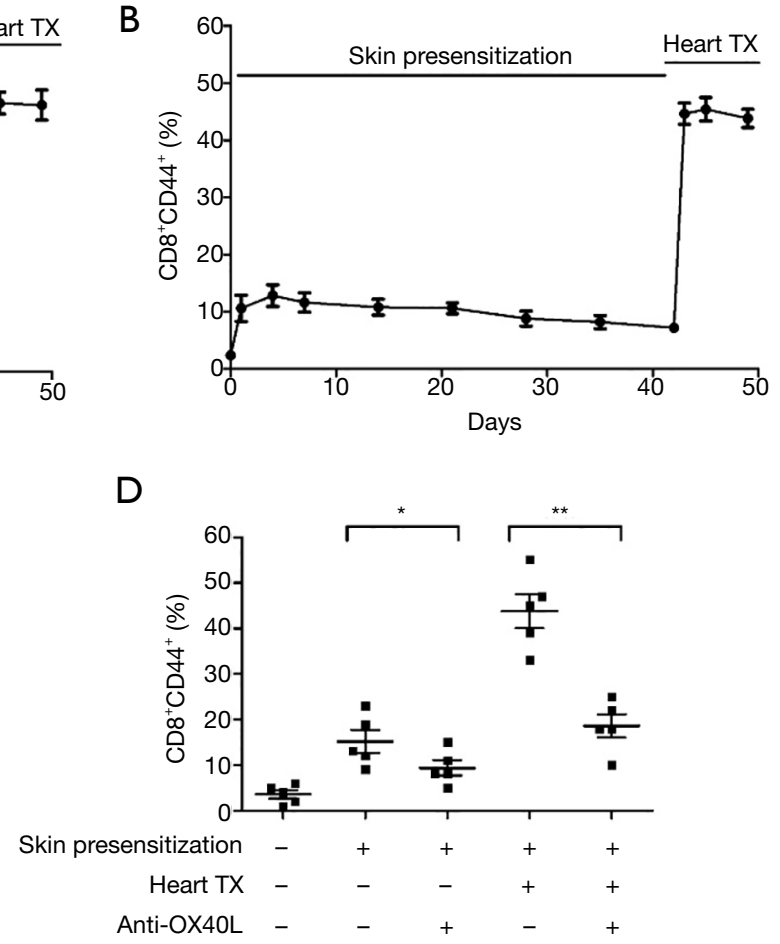

Figure 1 The trends of memory T-cell after presensitization and the effect of anti-OX40L mAb monotherapy on memory $\mathrm{T}$ cell populations in presensitized mice. (A,B) The trends of splenic memory T-cell populations detected by flow cytometry after skin-presensitization and heart transplantation $(n=3)$; (C,D) analysis of splenic memory T-cells from presensitized recipients with or without anti-OX40L mAb treatment. Splenocytes were isolated from skin presensitized mice (POD4) and anti-OX40L-treated mice $(\mathrm{POD} 12)$. *, $\mathrm{P}<0.05 ;{ }^{* *}, \mathrm{P}<0.01$.

$\mathrm{CD} 4^{+} \mathrm{CD} 44^{+}$and $\mathrm{CD} 8^{+} \mathrm{CD} 44^{+} \mathrm{T}$ cells in all presensitized mice, regardless of whether they received cardiac transplantation (Figure 1C,D).

\section{Combination of anti-OX40L $m A b$ and ECDI-SPs treatment induced long term graft survival in presensitized recipients}

ECDI-SPs are able to induce long-term cardiac graft survival (>100 days) in non-presensitized mouse recipients, as confirmed in previous results (25). However, this same treatment could only transiently prolong cardiac graft survival in skin-presensitized recipients, as all of the grafts were rejected by POD30 (Figure $2 A$ ). Since antiOX40L mAb monotherapy is able to inhibit Tms in vivo and has been confirmed to prolong heart graft survival in presensitized recipients $(21,31)$, we assumed that the combination of ECDI-SPs and anti-OX40L mAb could induce long-term survival or even tolerance in presensitized recipients. As anticipated, the combined therapy was effective in achieving long-term/indefinite cardiac allograft survival in presensitized recipients, with $66.7 \%$ of the recipients surviving $>100$ days (Figure $2 A$ ). In contrast, isotype control IgG alone or in combination with ECDISPs exhibited no significant differences compared to the untreated or ECDI-SPs-treated presensitized recipients.

Cardiac allografts were examined histologically by hematoxylin and eosin (HE) staining at different time points after heart transplantation. Accelerated rejection was witnessed in control cardiac allografts, with massive mononuclear cell and erythrocyte infiltration in the grafts. ECDI-SPs-treated mice were rejected by POD30, with typical characteristics of rejection. Anti-OX40L mAb was effective in prolonging heart graft survival, with decreased cellular infiltration by POD30. In contrast, in the antiOX40L mAb + ECDI-SPs treatment group, the graft tissues exhibited normal histology with minimal mononuclear cell infiltration up to POD100 (Figure 2B). 
A

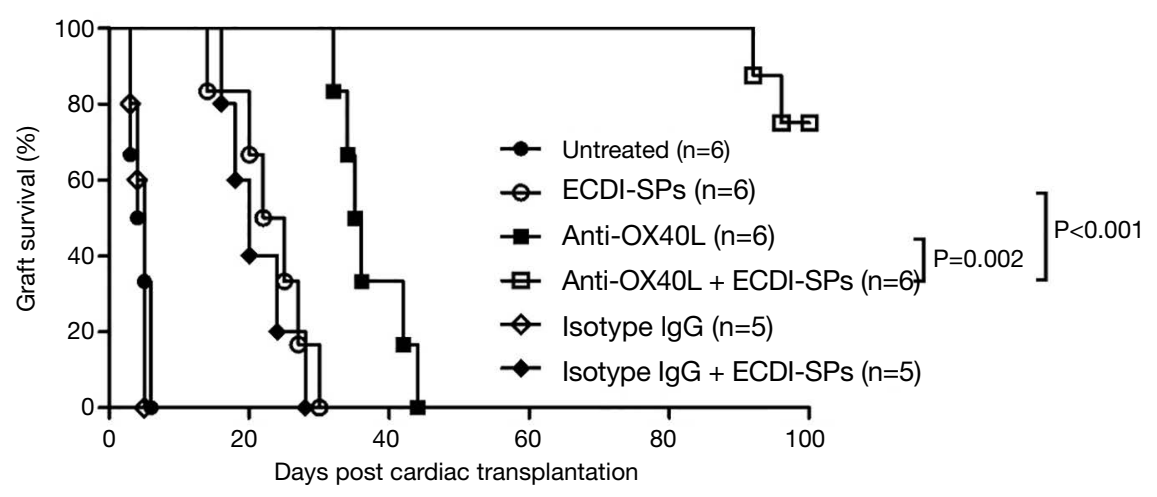

B
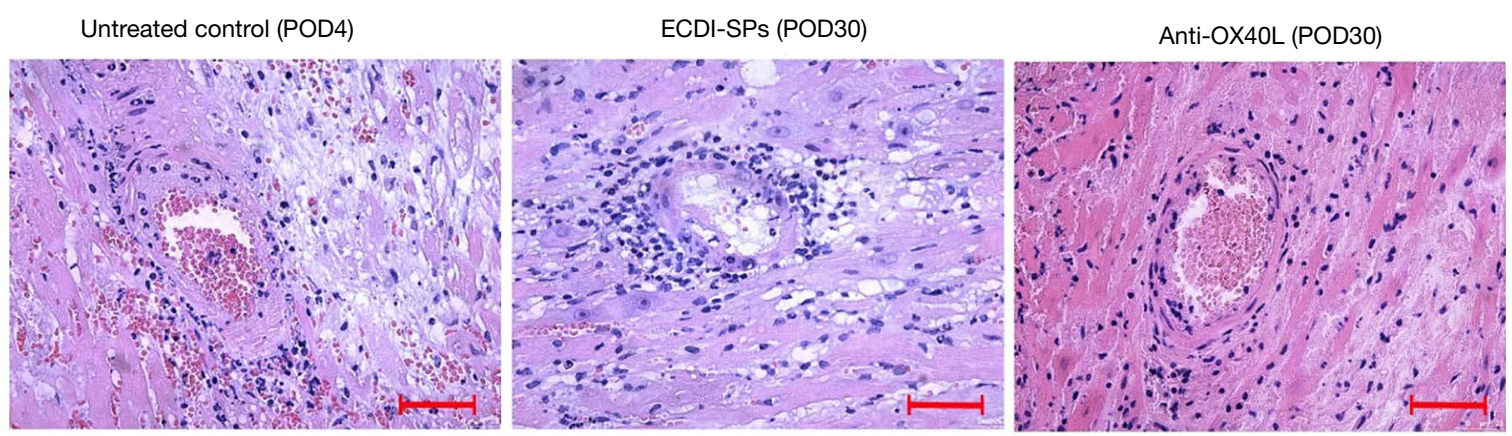

ECDI-SPs+anti-OX40L (POD30)

ECDI-SPs+anti-OX40L (POD100)
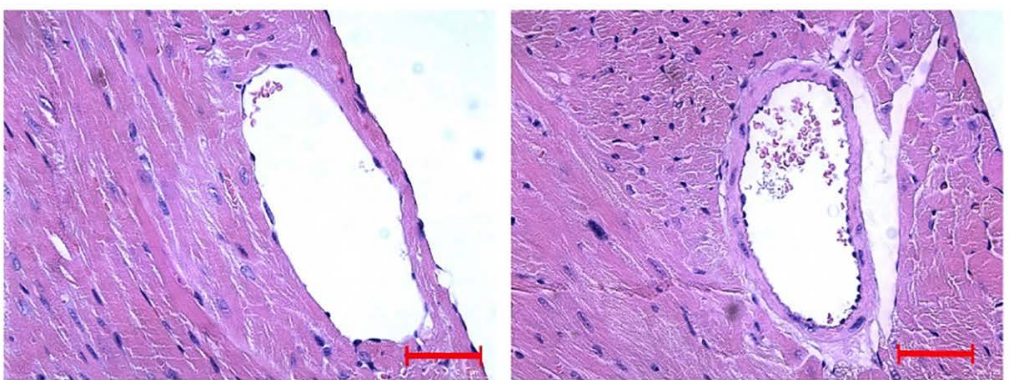

Figure 2 Effect of different treatments on presensitized heart transplant recipients. (A) Heart allograft survival times in skin-presensitized mice were analyzed by Kaplan-Meier analysis, and the difference between the groups was compared by the log-rank test; (B) the histologies of heart allografts of the different recipient treatment groups were compared by H\&E staining of paraffin sections. Magnification: $\times 400$. Bar: $50 \mu \mathrm{m}$.

\section{ECDI-SPs cooperated with anti-OX40L mAb in inbibiting expansion of Tms in presensitized recipients}

Analysis of memory $\mathrm{T}$ cell populations of the spleen demonstrated that treatment with ECDI-SPs alone could not prevent expansion of $\mathrm{CD} 4^{+} \mathrm{CD} 44^{+}$and $\mathrm{CD} 8^{+} \mathrm{CD} 44^{+}$ Tms in presensitized mice. In contrast, anti-OX40L $\mathrm{mAb}$ alone significantly decreased these Tm populations on both POD4 and POD30, compared with untreated controls and ECDI-SPs-treated recipients. Importantly, recipients receiving the combination of ECDI-SPs and anti-OX40L mAb treatment displayed appreciably low numbers of splenic Tms on POD 4 and persisted until POD100, indicating that ECDI-SPs cooperated with antiOX40L mAb in preventing Tms expansion (Figure $3 A, B$ ). However, presensitized recipients treated with isotype control IgG combined with ECDI-SPs exhibited no significant differences in either $\mathrm{CD} 4^{+} \mathrm{CD} 44^{+}$or $\mathrm{CD} 8^{+} \mathrm{CD} 44^{+}$ Tms populations as compared to the ECDI-SPs-treated recipients (data not shown). 
A
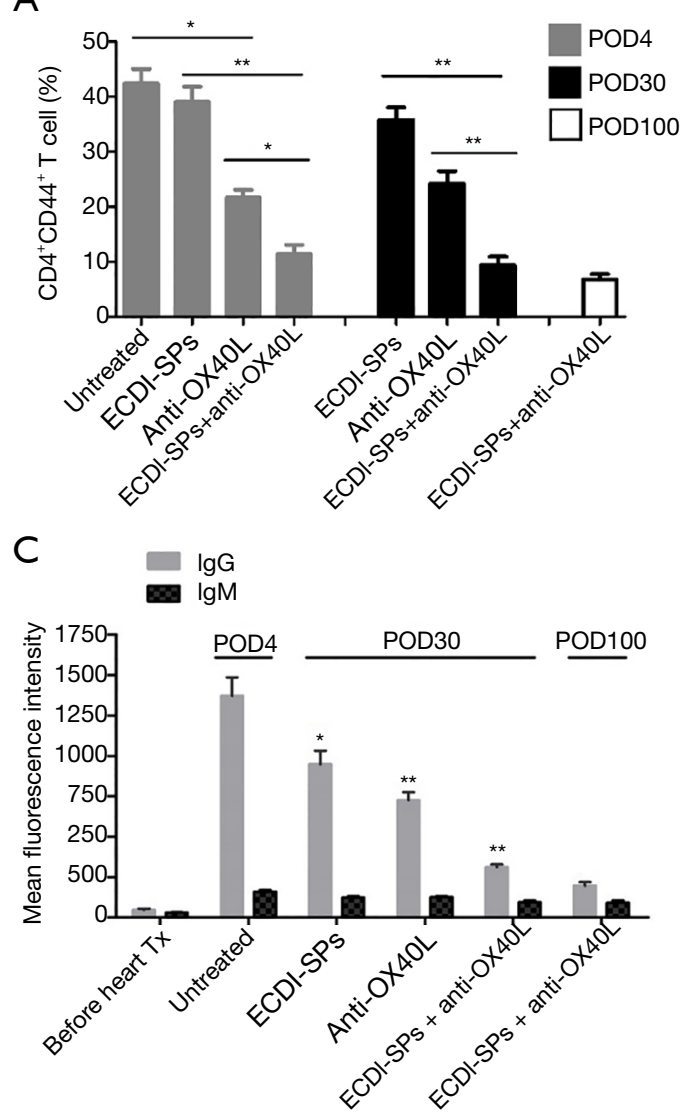

B

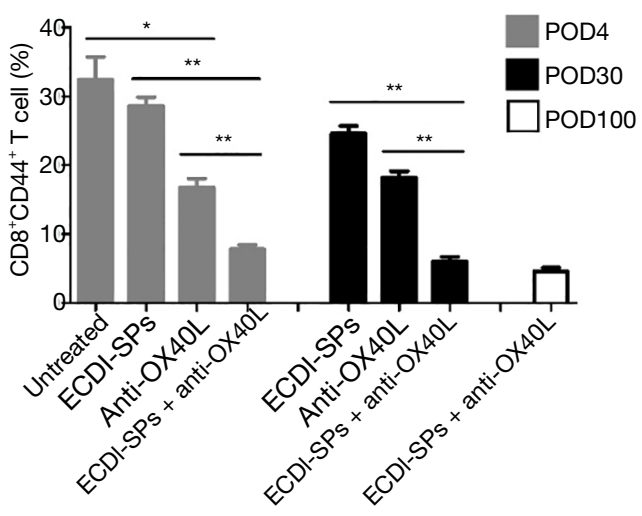

Figure 3 Effect of various treatments on memory $\mathrm{T}$ cell populations and serum levels of anti-donor antibodies in skin-presensitized mice. $(\mathrm{A}, \mathrm{B}) \mathrm{CD} 4^{+} \mathrm{CD} 44^{+}$and $\mathrm{CD} 8^{+} \mathrm{CD} 44^{+}$memory T-cell populations of recipients in different groups at the indicated time points $\left({ }^{*}, \mathrm{P}<0.05\right.$; ${ }^{* *}$, $\mathrm{P}<0.01)$; (C) serum levels of anti-donor antibodies in recipient mice. Sera was collected from different groups of recipients at the indicated time points and reacted with $\mathrm{BALB} / \mathrm{c}$ donor splenocytes. The $\operatorname{IgG}$ and $\operatorname{IgM}$ anti-donor antibody levels were evaluated by the binding of these antibodies with splenocytes using flow cytometry $\left({ }^{*}, \mathrm{P}<0.05 ;{ }^{* *}, \mathrm{P}<0.01\right.$ vs. the untreated group).

\section{Circulating anti-donor antibodies remained at low levels in combined-therapy-treated recipients}

Circulating anti-donor IgG antibodies were undetectable 6 weeks after skin presensitization, but quickly rose to a remarkably high level after heart transplantation from the same strain of donor by POD3. Interestingly, both antiOX40L mAb monotherapy and ECDI-SPs monotherapy could partially downregulate circulating anti-donor IgG response in all presensitized recipients. However, only the combined therapy could reduce and maintain the antidonor IgG at very low levels up to POD100. By contrast, serum anti-donor IgM antibodies were maintained at low levels and did not significantly change despite different treatments being given (Figure 3C), which was consistent with previous studies (21).

\section{Addition of anti-OX40L mAb to ECDI-SPs treatment influenced function of T cells in MLR in presensitized recipients}

To determine whether a state of tolerance had been induced by combined treatment, an in vitro MLR was assessed by using recipient $(\mathrm{C} 57 \mathrm{~B} / 6) \mathrm{DCs}$ as stimulators and donor $(\mathrm{BALB} / \mathrm{c}) \mathrm{CD}^{+} \mathrm{T}$ cells as responders. As shown in Figure $4 A$, DCs from recipients treated with anti-OX40L $\mathrm{mAb}$ alone or ECDI-SPs alone exhibited partially reduced stimulatory capacity as compared to DCs from untreated recipients. Importantly, DCs from combined therapy treated recipients showed markedly attenuated stimulatory capacity as compared to DCs from all other groups of recipients, and these DCs retained their impaired capacity to stimulate donor T cells up to POD100. 
A
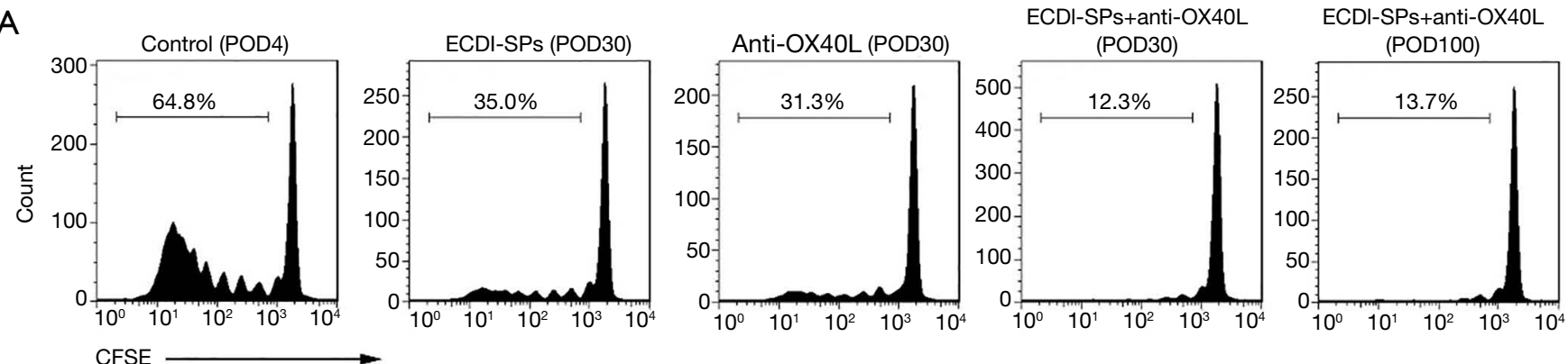

B

IFN $\gamma$

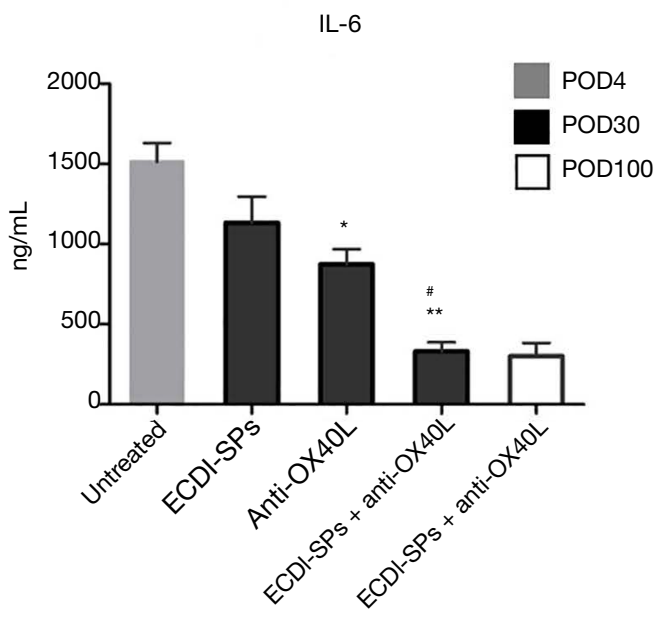

Figure $4 \mathrm{~T}$ cell proliferative responses of MLR and evaluation of sera pro-inflammatory cytokines. (A) Mixed lymphocytic reaction (MLR) in vitro was established by using splenic $\mathrm{CD} 11 \mathrm{c}+\mathrm{DCs}$ from recipients as stimulators and $\mathrm{CD} 3^{+} \mathrm{T}$ cells from donors as responders. T-cell proliferation was measured by CFSE dilution using flow cytometry; (B) evaluation of the serum levels of IFN- $\gamma$ and IL-6 ( $\mathrm{n}=3$ mice/group; *, $\mathrm{P}<0.05 ;{ }^{* *}, \mathrm{P}<0.01$ vs. the untreated control group; ${ }^{\prime}, \mathrm{P}<0.05$ vs. ECDI-SPs or the anti-OX40L group).

\section{ECDI-SPs combined with anti-OX40L mAb downregulate pro-inflammatory cytokines}

To investigate the combined effect of ECDI-SPs and antiOX $40 \mathrm{~L} \mathrm{mAb}$ on the pro-inflammatory cytokine expression profiles, serum IFN- $\gamma$ and IL-6 were measured. Notably, both IFN- $\gamma$ and IL- 6 were partially reduced by either ECDI-SPs or anti-OX40L mAb monotherapy, whereas the combined treatment of these two agents induced significantly lower levels of IFN- $\gamma$ and IL-6 compared to all of the other groups (Figure 4B).

\section{Anti-OX40L mAb combined with ECDI-SPs increased frequencies of splenic $\mathrm{CD} 4^{+} \mathrm{CD} 25^{+} \mathrm{Foxp}^{+} 3^{+}$Tregs}

We next tried to determine the influence of anti-OX40L $\mathrm{mAb}$ in combination with ECDI-SPs on Tregs in presensitized recipients, which was examined by analyzing frequencies of splenic $\mathrm{CD} 4^{+} \mathrm{CD} 25^{+} \mathrm{Foxp}^{+} \mathrm{T}$ cells. As shown in Figure 5, presensitized recipients receiving combined therapy displayed significantly higher frequencies of Tregs on POD30 and POD100, as compared to those recipients in all other groups. These results suggest that Tregs play a critical role in inducing graft tolerance under anti-OX40L $\mathrm{mAb}+\mathrm{ECDI}-\mathrm{SPs}$ treatment.

\section{Anti-OX40L mAb combined with ECDI-SPs failed to induce tolerance following CD25 $5^{+}$-cell depletion}

To determine whether $\mathrm{CD} 4^{+} \mathrm{CD} 25^{+} \mathrm{Foxp} 3^{+}$Tregs were indispensable in the induction of tolerance in combinedtherapy-treated presensitized recipients, we depleted $\mathrm{CD} 25^{+} \mathrm{T}$ cells by in vivo administration of anti-CD25 $\mathrm{mAb}$ (21). As shown in Figure 6A, following CD25 ${ }^{+}$T-cell depletion, all heart allografts were rejected by POD30, 
A

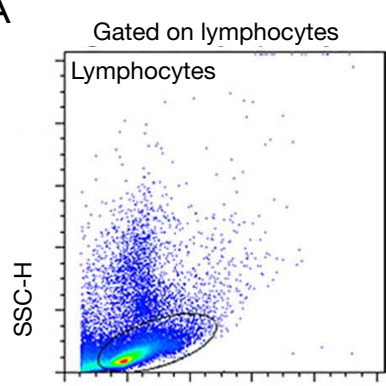

FSC-H

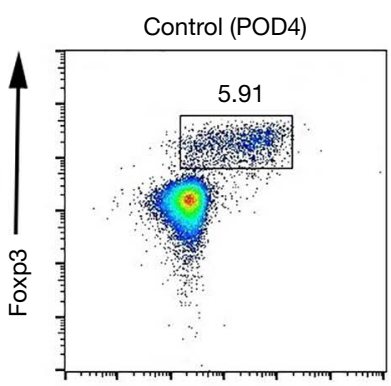

CD25

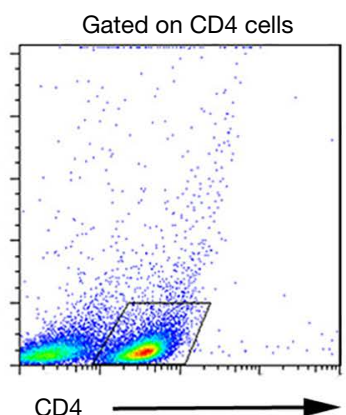

CD4
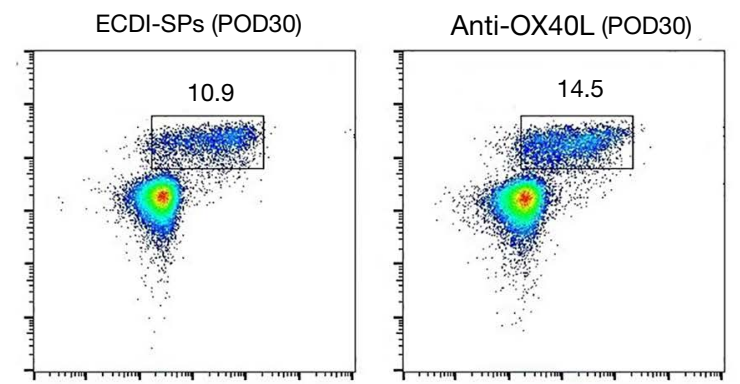

ECDI-SPs + anti-OX40L (POD100)

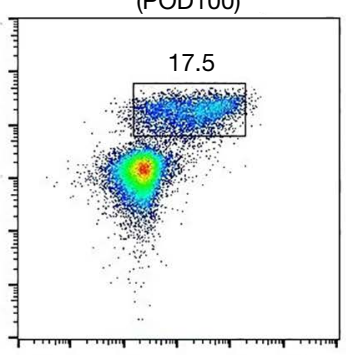

ECDI-SPs + anti-OX40L (POD30)

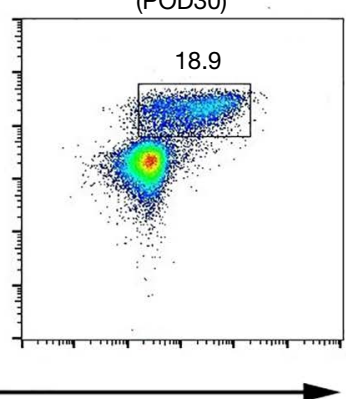

B

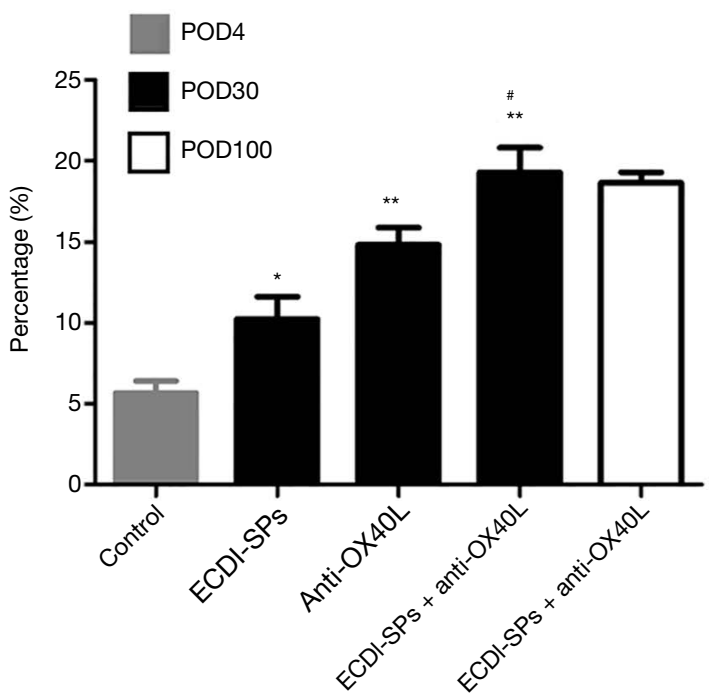

Figure 5 Anti-OX40L combined with ECDI-SPs promote Treg expansion. (A) Representative frequencies of CD25+Foxp3+ Tregs gated on $\mathrm{CD}^{+}$cells; (B) frequencies of splenic Tregs were expressed as mean $\pm \mathrm{SD}$ and analyzed by one-way ANOVA ${ }^{*}, \mathrm{P}<0.05 ;{ }^{* *}, \mathrm{P}<0.01$ vs. the untreated group; ${ }^{\#}, \mathrm{P}<0.05$ vs. ECDI-SPs or the anti-OX40L group).

although presensitized recipients were treated by combined therapy. In contrast, presensitized recipients administered with isotype control IgG + anti-OX40L mAb + ECDI-SPs maintained long-term graft survival. Importantly, following $\mathrm{CD} 25^{+} \mathrm{T}$-cell depletion, the splenic CD $25^{+} \mathrm{Foxp} 3^{+}$Tregs frequencies gated on $\mathrm{CD}^{+} \mathrm{T}$ cells significantly decreased to less than $5 \%$ at the time of rejection, indicating that most of the Tregs were depleted after anti-CD25 mAb use. As expected, by plus with isotype $\mathrm{IgG}$, the presensitized recipients treated with combined treatment remained at a high level of Tregs (Figure 6B). These results indicate that Tregs played a key role in the induction of tolerance which 
could be disturbed by anti-CD25 mAb.

\section{Tms break established allograft tolerance and suppress expansion of Tregs}

To investigate whether Tms were able to impede established graft tolerance, 6 weeks after skin presensitization, splenic $\mathrm{CD}^{+} \mathrm{T}$ cells containing massive $\mathrm{CD} 4^{+} / \mathrm{CD} 8^{+} \mathrm{CD} 44^{+} \mathrm{Tms}$ from presensitized mice were acquired. Then, these $\mathrm{T}$ cells were adoptively transferred into tolerogenic recipients treated with combined therapy on POD 30 and POD100.We found that all cardiac allografts were acutely rejected within 10-20 days following $\mathrm{CD}^{+} \mathrm{T}$ cell infusion, indicating that established allograft tolerance was inhibited or blocked. Importantly, this tolerance was donor-specific, as $\mathrm{T}$ cells from $\mathrm{C} 3 \mathrm{H}$ (third-party) skin-presensitized mice were unable to disturb established tolerance (Figure 6C). Consistent with the results of the survival curve, transfer of presensitized mice $\mathrm{T}$ cell into the combined treated recipients resulted in a marked decrease in Tregs frequency, either on POD30 or on POD100, compared to those recipients being transferred with $\mathrm{T}$ cells from $\mathrm{C} 3 \mathrm{H}$ (third party) skin-presensitized mice (Figure 6D).

\section{Discussion}

Tms have been identified as an obstacle in establishing tolerance induction in donor-antigen presensitized recipients. When activated by alloantigen, Tms can quickly and robustly expand and/or induce effector $\mathrm{T}$ cells, which impedes the induction of transplant immune tolerance, especially for secondary transplantation $(32,33)$. As was shown in our study, the percentage of $\mathrm{CD}^{+}$and $\mathrm{CD} 8^{+} \mathrm{Tms}$ were significantly increased after being stimulated by alloantigens, especially by the second stimulation. Previous literature indicates that the blockade of Tms is effective in prolonging cardiac allograft survival in presensitized recipients (34). Furthermore, recent studies have revealed that the OX40OX40L pathway has a diametric role in the interaction of Tms and Tregs in organ transplantation $(6,7,35)$. Tms are reliant on inducible OX40 to control their function and expansion $(12,36,37)$, and blocking OX40-OX40L pathway decreases the generation of Tms and increases the expansion of Tregs (18,38-40). Therefore, in our study, it is reasonable that the anti-OX40L mAb treatment resulted in a remarkable decrease of both $\mathrm{CD}^{+} \mathrm{Tms}$ and $\mathrm{CD} 8^{+} \mathrm{Tms}$, regardless of whether the mice received heart transplantation, which is consistent with previous studies (18).

ECDI-SPs have been shown to induce donor-specific immune tolerance in mouse islet cells and cardiac transplant models $(24,25,30)$, while prolonging mouse vascularized skin allograft survival (26). However, we found that ECDI-SPs treatment failed to prolong graft survival in presensitized mice. As anticipated, the addition of antiOX40L mAb to the ECDI-SPs protocol induced long-term graft survival and could even promote tolerance in skinpresensitized recipients, $66.7 \%$ of which survived more than 100 days. Heart allograft tissues from combined-therapytreated mice had the lowest level of inflammatory cell infiltration and maintained normal myocardial structure. These results indicate that anti-OX40L mAb could give assistance to ECDI-SPs in prolonging heart allograft survival in presensitized recipients.

We attempted to explore the potential mechanism of prolonged heart allograft survival induced by the combination of ECDI-SPs and anti-OX40L mAb. The results of flow cytometry showed that the addition of anti-OX40L mAb to ECDI-SPs could markedly reduce the levels of both $\mathrm{CD}^{+}{ }^{+} \mathrm{Tms}$ and $\mathrm{CD} 8^{+} \mathrm{Tms}$, which was beneficial for secondary allografts (41). It is clear that Tregs play a crucial role in protecting transplant allografts $(42,43)$. It has been reported that OX40/OX40L costimulation plays an important role in inhibiting TGF- $\beta$-mediated naïve $T$ cell conversion into Tregs, and that OX40 can abolish the suppressive function of Tregs $(7,20,44)$. In our study, the combination of anti-OX40L mAb and ECDISPs successfully induced and maintained high frequencies of Tregs in spleens. Specific depletion of CD25 $5^{+} \mathrm{T}$ cells in combined-therapy-treated presensitized recipients resulted in reduced levels of Tregs and broke tolerance. Accordingly, adoptive transfer of "memory-enriched" T cells can abolish established allograft tolerance and inhibit expansion of Tregs. All of these results suggest that the blockade of OX40/OX40L signaling pathway is favorable to creating a microenvironment for the induction of Tregs, through the inhibition of Tms (21).

The MLR results demonstrated that cell proliferation in the ECDI-SPs + anti-OX40L mAb group had the lowest cell proliferative response of all the groups. IFN $\gamma$ plays an important role in maximizing the function of effector $\mathrm{T}$ cells, while concomitantly preventing the induction of Tregs $(45,46)$. IL-6 induces naïve $\mathrm{T}$ cell differentiation into effector T cells (such as Th17), prevents the conversion of naïve $\mathrm{CD} 4^{+} \mathrm{Foxp}^{-} \mathrm{T}$ cells into $\mathrm{CD} 4^{+} \mathrm{Foxp}^{+}$ 
A

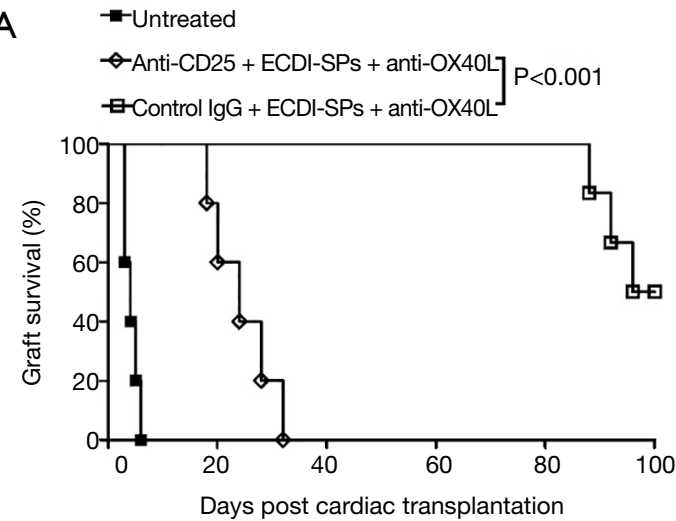

C

$\left.\begin{array}{l}- \text { - Transfer T cell on POD30 from presensitized mice } \\ \text { —- Transfer T cell on POD30 from 3rd-party presensitized mice }\end{array}\right] P<0.001$

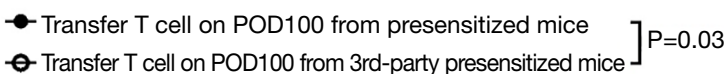

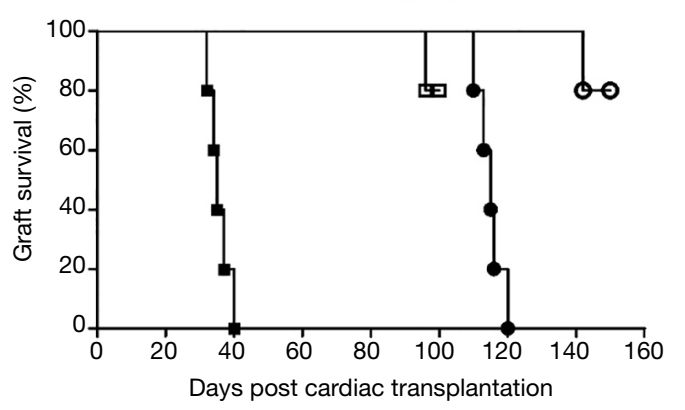

B

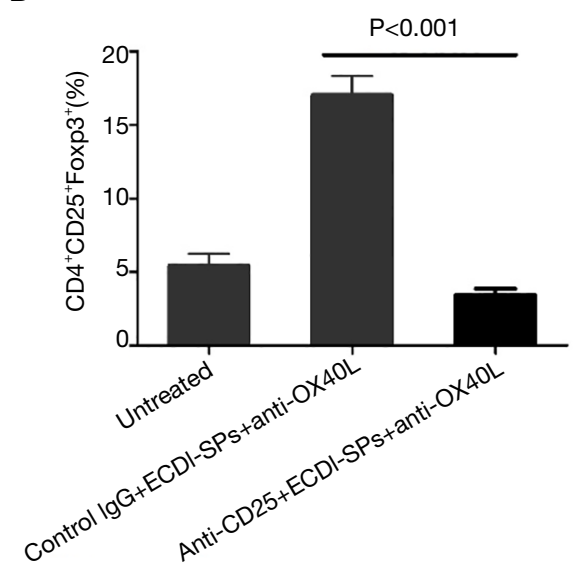

D

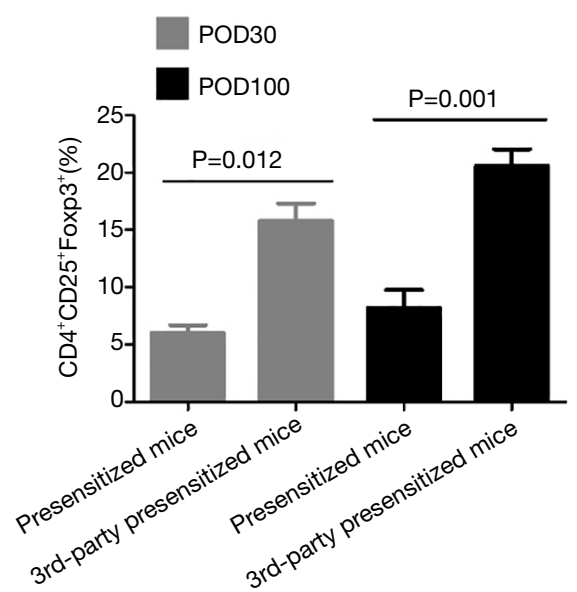

Figure 6 Effects of $\mathrm{CD} 25^{+}$cell depletion and adoptive transfer of presensitized-derived $\mathrm{T}$ cells on combined-treated presensitized recipients. (A) Survival of heart grafts of anti-OX40L mAb combined with ECDI-SPs therapy following CD25 cell depletion; (B) analysis of splenic Tregs frequencies in combined therapy-treated recipients after $\mathrm{CD} 25^{+}$cell depletion. Splenocytes were isolated from untreated control presensitized mice (POD4) or from combined therapy-treated mice receiving either anti-CD25 mAb or isotype control IgG (POD20). Data was analyzed by flow cytometry and results were expressed as percentages of $\mathrm{CD} 25^{+} \mathrm{Foxp} 3^{+}$cells within the $\mathrm{CD}^{+}$-gated cell population; (C) survival of heart grafts of combined therapy-treated presensitized recipients following adoptive T-cell transfer. T cells were isolated from $\mathrm{C} 57 \mathrm{~B} / 6$ mice either presensitized with $\mathrm{BALB} / \mathrm{c}$ or $\mathrm{C} 3 \mathrm{H}$ (third-party) skin-presensitized 6 weeks after skin transplantation and were adoptively transferred into combined therapy-treated presensitized recipients on POD30 or POD100 $\left(5 \times 10^{6}\right.$ per mouse); (D) analysis of splenic Tregs populations in combined therapy-treated presensitized recipients following T-cell transfer on POD30 and POD100. Data was analyzed by flow cytometry and results were expressed as percentages of $\mathrm{CD} 25^{+} \mathrm{Foxp} 3^{+}$cells within the $\mathrm{CD}^{+}{ }^{+}$-gated cell population.

Tregs, and inhibits the suppressive function of natural Tregs (47). In this study, we found that both of the IFN $\gamma$ and IL-6 levels in sera were significantly reduced when mice received treatment of ECDI-SPs in combination with anti-OX40L mAb. Overall, the results of cell proliferation and proinflammatory cytokine secretion show that the combination of ECDI-SPs and anti-OX40L mAb inhibited the function of $\mathrm{T}$ cells and created a cytokine milieu that favored Tregs induction $(45,48,49)$.

In summary, our study demonstrates that anti-OX40L $\mathrm{mAb}$ in combination with ECDI-SPs induces donor-specific immune tolerance in skin-presensitized heart transplant 
recipients. The mechanism of allograft protection includes the inhibition of memory $\mathrm{T}$ cell responses and the expansion of Tregs. Since presensitization is a major obstacle in clinic, inhibiting Tms by blockading OX40/ OX40L pathway combined with ECDI-SPs might have potential for clinical transplant therapy.

\section{Acknowledgments}

Funding: This study was supported by the Youth Scholar Project of the National Natural Science Foundation of China (No. 81601393, No. 31600746), the Scientific Research Project of the Higher Education Institutions of Guangzhou, (No. 1201630506), and the Fund of Guangzhou Institute of Pediatrics, Guangzhou Women and Children's Medical Center (No. 5001-3001009).

\section{Footnote}

Conflicts of Interest: The authors have no conflicts of interest to declare.

Ethical Statement: The authors are accountable for all aspects of the work in ensuring that questions related to the accuracy or integrity of any part of the work are appropriately investigated and resolved. All animal experiments were approved by the Institutional Animal Care and Use Committee of Guangzhou Medical University and conformed to the Institutional Guidelines of Guangdong Province (No. 2016-106).

\section{References}

1. Su Y, Ju MJ, Ma JF, et al. Lactate dehydrogenase as a prognostic marker of renal transplant recipients with severe community-acquired pneumonia: a 10-year retrospective study. Ann Transl Med 2019;7:660.

2. Bingaman AW, Farber DL. Memory T cells in transplantation: generation, function, and potential role in rejection. Am J Transplant 2004;4:846-52.

3. Lai X, Zhang L, Fang J, et al. OGTT 2-hour serum C-peptide index as a predictor of post-transplant diabetes mellitus in kidney transplant recipients. Ann Transl Med 2019;7:538.

4. Valujskikh A, Pantenburg B, Heeger PS. Primed allospecific $T$ cells prevent the effects of costimulatory blockade on prolonged cardiac allograft survival in mice. Am J Transplant 2002;2:501-9.
5. Rogers PR, Song J, Gramaglia I, et al. OX40 promotes $\mathrm{Bcl}-\mathrm{xL}$ and $\mathrm{Bcl}-2$ expression and is essential for long-term survival of CD4 T cells. Immunity 2001;15:445-55.

6. Croft M. Co-stimulatory members of the TNFR family: keys to effective T-cell immunity? Nat Rev Immunol 2003;3:609-20.

7. Chen M, Xiao X, Demirci G, et al. OX40 controls islet allograft tolerance in CD154 deficient mice by regulating FOXP3+ Tregs. Transplantation 2008;85:1659-62.

8. Godfrey WR, Fagnoni FF, Harara MA, et al. Identification of a human OX-40 ligand, a costimulator of CD4+ T cells with homology to tumor necrosis factor. J Exp Med 1994;180:757-62.

9. Baum PR, Gayle RR, Ramsdell F, et al. Molecular characterization of murine and human OX40/OX40 ligand systems: identification of a human OX40 ligand as the HTLV-1-regulated protein gp34. EMBO J 1994;13:3992-4001.

10. Chen AI, McAdam AJ, Buhlmann JE, et al. Ox40-ligand has a critical costimulatory role in dendritic cell: $T$ cell interactions. Immunity 1999;11:689-98.

11. Salek-Ardakani S, Song J, Halteman BS, et al. OX40 (CD134) controls memory $\mathrm{T}$ helper 2 cells that drive lung inflammation. J Exp Med 2003;198:315-24.

12. Zaini J, Andarini S, Tahara M, et al. OX40 ligand expressed by DCs costimulates NKT and CD4+ Th cell antitumor immunity in mice. J Clin Invest 2007;117:3330-8.

13. Gramaglia I, Jember A, Pippig SD, et al. The OX40 costimulatory receptor determines the development of CD4 memory by regulating primary clonal expansion. J Immunol 2000;165:3043-50.

14. Soroosh P, Ine S, Sugamura K, et al. OX40-OX40 ligand interaction through $\mathrm{T}$ cell- $\mathrm{T}$ cell contact contributes to CD4 T cell longevity. J Immunol 2006;176:5975-87.

15. Takasawa N, Ishii N, Higashimura N, et al. Expression of gp34 (OX40 ligand) and OX40 on human T cell clones. Jpn J Cancer Res 2001;92:377-82.

16. Yuan X, Salama AD, Dong V, et al. The role of the CD134-CD134 ligand costimulatory pathway in alloimmune responses in vivo. J Immunol 2003;170:2949-55.

17. Demirci G, Amanullah F, Kewalaramani R, et al. Critical role of OX40 in CD28 and CD154-independent rejection. J Immunol 2004;172:1691-8.

18. Vu MD, Clarkson MR, Yagita H, et al. Critical, but conditional, role of OX40 in memory T cell-mediated rejection. J Immunol 2006;176:1394-401. 
19. Valzasina B, Guiducci C, Dislich H, et al. Triggering of OX40 (CD134) on CD4(+)CD25+ T cells blocks their inhibitory activity: a novel regulatory role for OX40 and its comparison with GITR. Blood 2005;105:2845-51.

20. Vu MD, Xiao X, Gao W, et al. OX40 costimulation turns off Foxp3+ Tregs. Blood 2007;110:2501-10.

21. Ge W, Jiang J, Liu W, et al. Regulatory $T$ cells are critical to tolerance induction in presensitized mouse transplant recipients through targeting memory $\mathrm{T}$ cells. Am J Transplant 2010;10:1760-73.

22. Turley DM, Miller SD. Peripheral tolerance induction using ethylenecarbodiimide-fixed APCs uses both direct and indirect mechanisms of antigen presentation for prevention of experimental autoimmune encephalomyelitis. J Immunol 2007;178:2212-20.

23. Getts DR, Turley DM, Smith CE, et al. Tolerance induced by apoptotic antigen-coupled leukocytes is induced by PD-L1+ and IL-10-producing splenic macrophages and maintained by $\mathrm{T}$ regulatory cells. J Immunol 2011;187:2405-17.

24. Luo X, Pothoven KL, McCarthy D, et al. ECDIfixed allogeneic splenocytes induce donor-specific tolerance for long-term survival of islet transplants via two distinct mechanisms. Proc Natl Acad Sci U S A 2008;105:14527-32.

25. Chen G, Kheradmand T, Bryant J, et al. Intragraft $\mathrm{CD} 11 \mathrm{~b}(+) \mathrm{IDO}(+)$ cells mediate cardiac allograft tolerance by ECDI-fixed donor splenocyte infusions. Am J Transplant 2012;12:2920-9.

26. Ding J, Liu S, Zhang D, et al. Transfusion of ethylene carbodiimide-fixed donor splenocytes prolongs survival of vascularized skin allografts. J Surg Res 2018;221:343-352.

27. Wang H, Ge W, Arp J, et al. Free bone graft attenuates acute rejection and in combination with cyclosporin a leads to indefinite cardiac allograft survival. J Immunol 2009; 182:5970-81.

28. Xingqiang L, Fen N, Zhongpeng Y, et al. Ethylene carbodiimide-fixed donor splenocytes combined with cordycepin induce long-term protection to mice cardiac allografts. Transpl Immunol 2019;56:101196.

29. Ge W, Jiang J, Baroja ML, et al. Infusion of mesenchymal stem cells and rapamycin synergize to attenuate alloimmune responses and promote cardiac allograft tolerance. Am J Transplant 2009;9:1760-72.

30. Lai X, Qiu L, Zhao Y, et al. Ethylene carbodiimide-fixed donor splenocytes combined with alpha-1 antitrypsin induce indefinite donor-specific protection to mice cardiac allografts. Transpl Int 2017;30:305-17.
31. Dai H, Peng F, Lin M, et al. Anti-OX40L monoclonal antibody prolongs secondary heart allograft survival based on CD40/CD40L and LFA-1/ICAM-1 blockade. Transpl Immunol 2015;32:84-91.

32. Li XC, Kloc M, Ghobrial RM. Memory T cells in transplantation - progress and challenges. Curr Opin Organ Transplant 2013;18:387-92.

33. Su CA, Fairchild RL. Memory T Cells in Transplantation. Curr Transplant Rep 2014;1:137-46.

34. Dai H, Chen J, Shao W, et al. Blockade of CD27/CD70 pathway to reduce the generation of memory $T$ cells and markedly prolong the survival of heart allografts in presensitized mice. Transpl Immunol 2011;24:195-202.

35. Kinnear G, Wood KJ, Fallah-Arani F, et al. A diametric role for OX40 in the response of effector/memory CD4+ $\mathrm{T}$ cells and regulatory $\mathrm{T}$ cells to alloantigen. $\mathrm{J}$ Immunol 2013;191:1465-75.

36. Yamada A, Salama AD, Sayegh MH. The role of novel $T$ cell costimulatory pathways in autoimmunity and transplantation. J Am Soc Nephrol 2002;13:559-75.

37. Curry AJ, Chikwe J, Smith XG, et al. OX40 (CD134) blockade inhibits the co-stimulatory cascade and promotes heart allograft survival. Transplantation 2004;78:807-14.

38. Ruby CE, Redmond WL, Haley D, et al. Anti-OX40 stimulation in vivo enhances CD8+ memory $\mathrm{T}$ cell survival and significantly increases recall responses. Eur J Immunol 2007;37:157-66.

39. Sugamura K, Ishii N, Weinberg AD. Therapeutic targeting of the effector T-cell co-stimulatory molecule OX40. Nat Rev Immunol 2004;4:420-31.

40. Wang H, Zhang Z, Tian W, et al. Memory T Cells Mediate Cardiac Allograft Vasculopathy and are Inactivated by Anti-OX40L Monoclonal Antibody. Cardiovasc Drugs Ther 2014;28:115-22.

41. Setoguchi K, Schenk AD, Ishii D, et al. LFA-1 antagonism inhibits early infiltration of endogenous memory CD8 $\mathrm{T}$ cells into cardiac allografts and donor-reactive $\mathrm{T}$ cell priming. Am J Transplant 2011;11:923-35.

42. Cobbold SP, Waldmann H. Regulatory cells and transplantation tolerance. Cold Spring Harb Perspect Med 2013;3:a015545.

43. Hilbrands R, Howie D, Cobbold S, et al. Regulatory $\mathrm{T}$ cells and transplantation tolerance. Immunotherapy 2013;5:717-31.

44. So T, Croft M. Cutting edge: OX40 inhibits TGF-betaand antigen-driven conversion of naive CD4 $\mathrm{T}$ cells into CD25+Foxp3+ T cells. J Immunol 2007;179:1427-30.

45. Xiao X, Kroemer A, Gao W, et al. OX40/OX40L 
costimulation affects induction of Foxp3 + regulatory $\mathrm{T}$ cells in part by expanding memory $\mathrm{T}$ cells in vivo. $\mathrm{J}$ Immunol 2008;181:3193-201.

46. St Rose MC, Taylor RA, Bandyopadhyay S, et al. CD134/ CD137 dual costimulation-elicited IFN-gamma maximizes effector T-cell function but limits Treg expansion. Immunol Cell Biol 2013;91:173-83.

47. Zhang C, Zhang X, Chen XH. Inhibition of the interleukin-6 signaling pathway: a strategy to induce

Cite this article as: Lai X, Yao Z, Ning F, Zhang L, Fang J, Li G, Xu L, Xiong Y, Liu L, Chen R, Ma J, Chen Z. Blockade of OX40/OX40L pathway combined with ethylenecarbodiimide-fixed donor splenocytes induces donor-specific allograft tolerance in presensitized recipients. Ann Transl Med 2020;8(4):84. doi: 10.21037/atm.2019.12.146 immune tolerance. Clin Rev Allergy Immunol 2014;47:163-73.

48. Wei J, Duramad O, Perng OA, et al. Antagonistic nature of $\mathrm{T}$ helper $1 / 2$ developmental programs in opposing peripheral induction of Foxp3 + regulatory T cells. Proc Natl Acad Sci U S A 2007;104:18169-74.

49. Morelli AE, Thomson AW. Tolerogenic dendritic cells and the quest for transplant tolerance. Nat Rev Immunol 2007;7:610-21. 